“Historical Studies on Mortality,” special issue, Canadian Studies in Population 39, no. 3-4 (2012): 137-138.

\title{
Migration and Mobility in Europe: Trends, Patterns, and Control
}

\author{
Edited by Heinz Fassmann, Max Haller, and David Lane \\ Northampton, MA: Edward Elgar, 2009 \\ ISBN 978-1848443716 \\ Hardcover, \$135.00, 312 pp.
}

\author{
Reviewed by Alan Simmons \\ Department of Sociology, York University \\ asimmons@yorku.ca
}

Over the past half-century, Europe has experienced an enormous expansion of "internal" (within Europe) crossborder migration and mobility. This book-consisting mostly of edited versions of the best papers presented in a 2007 conference - provides a welcome update on overall patterns and emerging issues. Fifteen individually authored chapters (in total, 296 pages plus an index) cover the motivation of the migrants, who wins and who loses from migration, the main countries of origin and destination, integration issues, and state migration controls in an era of globalized crime and terrorism. The authors include sociologists, regional planners, political scientists, demographers, and economists from European nations and Turkey, a nation aspiring to become a member of the European Economic Union.

Overall patterns are well summarized in the introductory chapter. Following the closing of migration flows during the great wars and the 1930s depression, the previously established patterns of expanding migration flows within Europe resumed in what may be termed "a second great migration drift" led by southern Europeans who moved to northwestern Europe for jobs. The great drift took new directions from 1989 on, as Eastern Europeans moved in large numbers to Northern, Western, and Southern Europe. Within the region, currently, about 3.65 million people (or 8.8 percent of Europe's 40 million inhabitants) are foreign-born. Less than half of these have adopted citizenship in their countries of destination. Recent movements have significant elements of circulation and impermanence. Motivation is largely job-related, with low-wage employment markets driving much of the movement.

New patterns and questions are emerging. Complex patterns of who loses and who benefits from migration continue to spark debate in the region; women are migrating independently much more than before; and circulation and related transnational social networks continue to expand. The social integration of migrants and the effectiveness and impact of rapidly evolving state efforts to use migration controls as tools to address international crime and terrorism are not well understood. Specific chapters in the book address these diverse new issues and research challenges.

Part I of the book consists of four chapters broadly on costs and benefits of migration. Consistent with global patterns of migration, research on the flows within Europe indicates that migrants themselves are the main and clearest beneficiaries (Chapter 2). The communities they leave and where they go lose or benefit variably, in complex and often mixed ways that defy simple generalizations. The claim that migrants are required to fill "labor force shortages" is sometimes substantiated, but in other cases is simply a myth that favors employers seeking low-wage workers (Chapter 3). Empirical evidence confirms that most Europeans would rather not move and only migrate when economic circumstances require them to do so (Chapter 4). Young Portuguese workers provide a specific example of a particular pattern of low emigration: few young workers move abroad despite high youth unemployment at home. This is because they do not have the resources to move abroad for study or to find jobs, and because they are dependent on community and family support in their home towns (Chapter 5).

Surprisingly, data to analyze overall European migration trends over time and patterns across nations are scarce. Part II of the book consists of five chapters on contemporary patterns of migration and mobility based on studies that cast light into this area. Information gathered from 1974 to 2003 in the International Migration Survey reveals 
that while many migrants move for low wage jobs, others from high social status background move for study abroad. Those who move for study purposes are the best integrated (Chapter 6). Polish emigration patterns are telling with respect to new trends, such as the rising proportions of women; more circulation, and the rise of transnational social links (Chapter 7). Increasing numbers of Europeans are moving to Turkey for retirement, such that particular Turkish destination communities are being transformed socially (Chapter 8).

Studies of the integration of European migrants within Europe appear to be less common than one might expect. Perhaps this explains why Part III on integration issues contains only two chapters. Chapter 11 examines the integration of Turkish migrants in five different European destination places. The integration levels and issues vary from one destination place to another because the destination societies are different, and also because the Turkish migrants in each case come from different regions and sub-cultures in Turkey. The other chapter (Chapter 12) examines population register data on return migrants in Finland. The data show that return migrants suffer high levels of unemployment to begin with, that their disadvantages in the labor market decline only slowly over many years, and most surprisingly that duration of residence abroad — an indicator of loss of contact with the Finish labor marketis not strongly related to their disadvantage. No information is available on the motives of the migrants and whether the migrants include many individuals who also had poor job success abroad before returning. More research on migrant integration in Europe is a priority.

Few migration topics have generated more controversy in recent years in Europe and elsewhere than that of state control of borders. Part IV brings the book to a close with three chapters on this topic. The first of these (Chapter 13) situates the emerging issues within the framework of a "migration state," namely, a trade-competitive state that seeks advantages by opening its economy and society to inflows of both low-wage migrants and highly skilled migrants. In so doing, a migration state must address public antipathy to the cultural changes the migrants bring, fears that the migrants are stealing jobs, and anxiety over links between migrants and international crime and terrorism. Migration control in such a context consists of a complex risk management process. The second chapter (Chapter 14) examines how electronic surveillance generated through border controls is evolving and how other measures - such as controls on employers to insure they do not employ illegal migrants-are being introduced. The final chapter (Chapter 15) is a study of how border controls impact on human rights and the right of asylum in the case of Norway.

In sum, this book will be of particular interest to graduate students and researchers in the field. It provides for them a valuable collection of recent research papers on contemporary European migration developments and research priorities. 